\title{
Mermi Çekirdeği Silinti Halkasının Değerlendirilmesinde Dikkat Çeken Farklılıklar
}

\author{
Striking Differences in Assessment of Bullet Wipe
}

\author{
Gökçe Karaman, M. Hakan Özdemir
}

Dokuz Eylül Üniversitesi Tıp Fakültesi Adli Tıp Anabilim Dalı, İmir

Silinti halkası, ateşli silah mermi çekirdeği giriş yaralarında ciltte ve/veya giyside meydana gelebilmektedir.

Adli tıp uygulamalarında silinti halkasının tanımı ve özellikleri, medikolegal değerlendirmede önemli olabilmektedir. Yaptığımız literatür taramasında silinti halkasının özellikleri, nasıl oluştuğu hakkında yabancı ve yerli yayınlarda farklı yorumlar olduğunu gördük. Bunları okuyucularla paylaşmak istedik.

Öncelikle yerli kaynaklara baktığımızda;

Prof. Dr. Şemsi Gök hocamız, mermi çekirdeğinin namludan geçerken yiv ve setlerin arasında bulunan yağ,is ve pası üzerine sardığını, bu çekirdeğin cildi delip geçerken üzerindeki kiri deliğin etrafina bulaştırdığını, buna silinti halkası denildiğini, silinti halkasının namlusu kirli silahlarla meydana geldiğini ve 2-3 üncü atımlardan sonra namlu temizlendiği için görülmeyeceğini belirtmektedir (1).

Prof. Dr. İbrahim Tunalı, giriş deliğinin çevresinde merminin deriyi sıyırması ve deri üzerinde merminin kir, pas ve duman islerinin kalması neticesinde kontüzyon halkası ve silinti şeridinin meydana geldiğini, silinti şeridinin kontüzyon halkasının iç tarafında ikinci bir halka olarak görüldügünü belirtmektedir (2).

Prof. Dr. Oğuz Polat ve arkadaşları, vurma halkasının iç kenarında mermi çekirdeği üzerinde bulunan materyalin (yağ, is, metal parçacıkları), deri çevresindeki veya elbise üzerindeki delik kenarlarında kalması sonucu silinti halkasının meydana geldiğini ve bu izin ancak ilk birkaç atışta görüleceğini belirtmektedir $(3,4)$.

Prof. Dr. Gürsel Çetin ve Prof. Dr.Coşkun Yorulmaz tarafından silinti halkasının silah ateş edildikten sonra mermi çekirdeği namludan geçerken namlunun daha önceden yağlanması sonucu namluda bulunan yağın veya namlu yeni yağlanmamışsa eski yağ artıkları, is ve pasın mermiye bulaşması ve mermi çekirdeğinin cildi delip girdiği esnada çekirdek üzerindeki bu maddelerin giriş deliğinin ağzında çepeçevre bir leke oluşturması sonucu oluştuğu ve genellikle aynı silahla yapılan ilk birkaç atışta meydana geldiği belirtilmektedir (5).

Prof. Dr. H. Bülent Üner ve arkadaşı, silah ateşlendiğinde namlu içinde sürtünerek ilerleyen mermi çekirdeğinin yivler arasına yerleşmiş olabilen yağ, is ve pası da üzerine alıp namludan çıktıktan sonra hedefe girerken bu kirlerin giriş deliğine bulaştığını, bu koyu gri siyah renkteki ize silinti halkası denildiğini ve ilk atışlarda daha net görüldüğünü belirtmektedir (6).

Prof. Dr. Yaşar Bilge de kontüzyon halkası ile giriş deliği arasında, milimetre ile ifade edilebilecek kadar dar bir alanda, mermi üzerindeki yağ, pas ve is bulaşmasıyla bir bölge daha oluştuğunu, bu alana silinti şeridi adı verildiğini, silinti şeridinin giriş deliği etrafındaki şeklinin de aynı vurma halkasında olduğu gibi atış yönüne bağlı olarak oluştuğunu belirtmektedir (7).

Yabancı kaynaklara baktığımızda;

Pekka Saukko ve Bernard Knight, abrazyon halkas1nın iç kenarının, 1Sı etkisi ve mermiden kaynaklanan kir, lubrikant, yağ veya gres yağ ve metal partiküllerinin silinmesi sonucu siyah bir renk alabileceğini ve bunun silinti halkası olarak adlandırıldığını, eğer mermi temiz ise görülmeyeceğini belirtmektedir (8).

Edward E. Hueske, silinti halkasının; merminin geçişi esnasında mermi üzerindeki is ve yağın cisim kenarlarına (Örnek: cilt, kumaş, tahta, deri) transfer olmasıyla oluştuğu, silinti halkasının her zaman bulunmayacağı, bulunsa bile görülmesinin pıhtılaşmış kan veya koyu renkte giysi veya cisim nedeniyle zor olabileceği belirtilmektedir (9).

Brian J. Heard, mermi üzerinde bulunan lubrikantın, kovan ağzı dolgu maddesinin (bullet/case mouth sealant) ve gazların, merminin namludan geçişiyle namludan ç1kan merminin isli bir materyalle sarılmasına neden olacağını ve merminin ciltten, giysiden veya başka bir solid 
cisimden geçişi esnasında bu siyah renkteki maddenin giriş deliğinin çevresinde birikeceğini, bu halkaya silinti halkası denildiğini, halkadaki materyal miktarının, üzerinde biriken karbon materyalin miktar ile orantılı olduğunu, mermi çekirdeği giriş yarasının yararlı bir belirteci olduğunu, temiz bir namlu ile yapılan birinci atıştan sonra meydana gelen silinti halkasının, namlunun kirlenmesine neden olmasından dolayı ikinci atıştan sonra meydana gelen silinti halkasından ayrımının kolayca yapılabileceğini (ilk atış sonucu meydana gelen silinti halkasının ikinci atışa göre daha soluk görüneceği), birden fazla kez atış yapılmış olgularda makul bir doğruluk derecesine kadar hangi atışın önce yapıldığının tespit edilmesinin mümkün olduğunu belirtmektedir (10).

Jeanine Vellema ve Hendrik Scholtz, uzak atışlarda abrazyon halkasının yanında merminin namlu içinde ilerlemesi sırasında mermi üzerinde biriken barut artıkları, is, yağ veya kirin merminin vücuda girişi esnasında cilt tarafından silinmesi sonucu gri renkli silinti halkasının oluştuğunu, yaygın olarak giriş yarasının üzerindeki giyside gözlendiğini, üzerinde primere, mermi çekirdeğine ve kovana ait metalik maddeler bulunabileceğinden, meydana gelen yaranın silahla ilişkilendirilmesi açısından değeri olabileceğini belirtmektedir (11).

Markus A. Rothschild, silinti halkasının tanımında; mermi çekirdeğinin namludan geçerken yağ, önceki atışlardan kalan barut (itici madde) ve patlamaya ait maddeleri üzerine aldığını, cilde girişi esnasında bu materyallerin giriş yarasına silindiğini, yaklaşı 1-3 mm genişliğinde, koyu renkte, parlak bir halka oluşacağını belirtmektedir (12).

Bernd Karger, silinti halkasının cilt defekti etrafında ince, yuvarlak, siyahımsı renk değişimi olduğunu, atış artıkları, yağ, kir, merminin ve namlunun abrazyonuyla ortaya çıkan materyalin, ilk giriş sırasında mermi ucundan yara kenarlarına silinmesi sonucu oluştuğunu belirtmektedir (13).

Reinhard B. Dettmeyer ve arkadaşları, mermi üzerindeki yağ artıklarının ateşli silah giriş yarasının kenarlarında birikerek siyah renkte halka oluşturduğunu ve buna silinti halkası denildiğini, görünürlüğünün namlu içindeki kir miktarına bağlı olduğunu, eğer mermi giysi üzerinden geçerse silinti halkasının giriş yarasından ziyade giysinin dış tabakası üzerinde görünür olacağını belirtmektedir (14).

Vincent J. M. Di Maio, silinti halkasının giriş yarasında abrazyon halkasının yanında, meydana gelen gri renk değişimi olduğunu ve giysiler üzerinde daha fazla ve belirgin olarak görüldüğünü, esasen merminin namlu- dan ilerlemesi esnasında mermi yüzeyine bulaşan 'is'in, merminin cilt veya giysiye penetrasyonu esnasında sürünmesi sonucu oluştuğunu, lubrikant maddelerin ve primerden, kovandan ve mermiden gelen az miktardaki metalik maddenin de silinti halkasında bulunabileceğini, namlu içinde bulunan daha önceki atışlara ait artıkların da mermiye bulaşabileceğini ve özellikle merminin tabanına atış esnasında yanmamış barut tanelerinin de yapışabileceğini, bitişik atışlarda görülen is ve yanıkla karıştırılmaması gerektiğini, silinti halkasının gömleksiz mermi çekirdeklerinin bir özelliği olduğu söylense de bunun doğru olmadığı, tam gömlekli mermilerle de silinti halkasının meydana gelebileceğini, eğer namlunun içerisi hiçbir materyal kalmayana dek temizlenirse, yapılan atış sonrasında giysi üzerinde açık gri renkte ve neredeyse görülemeyen bir silinti halkasının meydana geleceğini, aynı silahla yapılan tekrarlayan atışlar sonucunda silinti halkasının giderek daha koyu bir hale geleceğini ve sonunda belli bir koyulukta stabilize olacağını belirtmektedir (15).

Literatürde aynı silahla yapılan tekrarlayan atışlar sonucunda silinti halkasının giderek daha koyu bir hale geleceğine yönelik atıflar bulunmaktadır (16).

Sonuç olarak; yerli kaynaklar silinti halkasını esas olarak namluda bulunan yağ, kir, pas ve isin meydana getirdiği, yapılan atışlar sonrası namlu içindeki kirin giderek azalacağı ve bu nedenle silinti halkasının ilk atışlarda daha net görüleceği veya ilk birkaç atıştan sonra görülmeyeceği belirtilmektedir $(1,2,5,6)$.

Di Maio ise, silinti halkasını esas olarak namludaki isin meydana getirdiğini, lubrikant maddelerin, primerden, kovandan ve mermiden gelen az miktardaki metalik maddenin de silinti halkasında bulunabileceğini belirtmektedir. Bu nedenle temiz bir namlu ile yapılan ilk atışlarda silinti halkasının görülemeyecek kadar soluk olabileceğini ancak tekrarlayan atışlar sonucunda silinti halkasının giderek daha belirgin hale geleceğini belirterek (15) incelediğimiz yerli kaynaklardan farklı bir görüş ileri sürmektedir. Brian J. Heard da aynı şekilde namlusu temizlenmiş bir silahla yapılan ilk atışlarda silinti halkasının soluk olarak görüneceğini, sonraki atışlarda silinti halkası üzerinde daha fazla karbon materyal bulunacağı için giderek daha belirgin hale geleceğini belirterek Di Maio'nun görüşünü desteklemektedir (10).

Silinti halkasının ilk atışlarda belirgin ve /veya soluk görülmesi ile ilgili kaynaklar arası farklılıkların, bu olguların değerlendirilmesi açısından önemli olabileceğini kaynaklar arasındaki farklılıkları paylaşarak tartışmaya açmak istedik. 


\section{Kaynaklar}

1. Gök Ş. Adli Tıp, 6th ed. İstanbul: Filiz Kitabevi; 1991. p. 209.

2. Yunalı İ. Adli Tıp, 2nd ed. Ankara: Atilla Kitabevi; 1991. p. 109.

3. Polat O, İnanıcı MA, Aksoy ME. Adli Tıp Ders Kitabı. İstanbul: Nobel Tıp Kitabevleri Ltd Şti; 1997. p. 116.

4. Polat O. Adli Tıp, 2nd ed. İstanbul: Der Yayınları; 2001:269.

5. Çetin G, Yorulmaz C. Ateşli Silah Yaraları In: Soysal Z, Çakalır C. eds. Adli Tıp Cilt 2. İstanbul: İstanbul Üniversitesi Cerrahpaşa Tıp Fakültesi Yayınlarından; 1999:570-71.

6. Üner HB, Çakır İ. Adli Balistik. İstanbul: Arıkan Basım Yayım Dağıtım Ltd Şti; 2007. p. 88.

7. Bilge Y. Adli Tip. 2nd ed. Ankara: Nobel Tıp Kitabevi Ltd. Şti; 2008. p. 96.

8. Gunshot and explosion deaths. In: Saukko P, Knight B, editors. Knight's Forensic Pathology. 3rd ed. London: Edward Arnold; 2004. p. 245-300.

9. Hueske EE. Practical Analysis and Reconstruction of Shooting Incidents. Boca Raton, FL: CRC Press; 2006. p. 165.

10. Heard BJ. Handbook of firearms and ballistics : examining and interpreting forensic evidence. Oxford; Hoboken, NJ: Wiley-Blackwell; 2008. p. 226.

11. Vellema J, Scholtz H. Forensic Aspects of Ballistic Injury. In: Brooks JA, Clasper J, Midwinter M, Hodgetts JT, Ma- honey FP, editors. Ryan's Ballistic Trauma: A Practical Guide. London: Springer London; 2011. p. 149-75. doi: 10.1007/978-1-84882-124-8_12.

12. Rothschild MA. Wound Ballistics and Forensic Medicine. In: Kneubuehl BP, editor. Wound Ballistics Basics and Applications. 3rd ed. Heidelberg: Springer; 2011. p. 257-58. doi: 10.1007/978-3-642-20356-5_5.

13. Karger B, Madea B. Forensic Ballistics: Injuries from Gunshots, Explosives and Arrows. Handbook of Forensic Medicine: John Wiley \& Sons, Ltd; 2014. p. 328-66. doi: 10.1002/9781118570654.ch20.

14. Dettmeyer RB, Verhoff MA, Schütz HF. Gunshot and Blast Wounds. Forensic Medicine: Fundamentals and Perspectives. Berlin, Heidelberg: Springer Berlin Heidelberg; 2014. p. 155-70. doi: 10.1007/978-3-642-38818-7_10.

15. DiMaio VJM. Detection of Gunshot Residues. Gunshot Wounds. Practical Aspects of Criminal \& Forensic Investigations. 3rd ed: CRC Press; 2016. p. 287-304. doi: 10.1201/ b18888-13.

16. Kieser DC, Carr DJ, Girvan L, Leclair SCJ, Horsfall I, Theis JC, et al. Identifying the source of bullet wipe: a randomised blind trial. Int J Legal Med. 2013;127(5):951-5. doi: 10.1007/s00414-013-0874-z. 